\title{
Delivering a large cohort simulation - beginning nursing students' experience: A pre-post survey
}

\author{
Rebecca T. Disler, Suzanne F. Rochester, Michelle A. Kelly, Haidee White, J an Forber \\ Faculty of Health, University of Technology, Sydney, Australia
}

Correspondence: Rebecca Disler. Address: Faculty of Health, University of Technology, Sydney, PO Box 123, Broadway, NSW 2007, Australia. Email: rebecca.disler@uts.edu.au.

Received: September 26, 2012

Accepted: May 15, 2013

Online Published: July 31, 2013

DOI : 10.5430/jnep.v3n12p133

URL: http://dx.doi.org/10.5430/jnep.v3n12p133

\section{Abstract}

Background: The use of simulation has been growing rapidly within nursing programs, internationally. Simulation provides opportunity for beginning nursing students to rehearse patient care experiences and develop confidence in technical and non-technical nursing skills.

Methods: This study used a quantitative pre-post online survey to investigate: the components of the integrated simulation experience that assisted with learning; students' confidence in caring for patients comparable to patients experienced in the simulation and their overall satisfaction with the simulation experience.

Results: A total of 480 students participated in a simulation prior to clinical practicum and 452 (94.16 completed the survey questions). Guidance by the academic and clinical facilitator, and the film watched prior to participating in the active simulation encounter, were highlighted as components which provided most assistance to students in their learning. A significant increase in confidence in caring for patients like those in the integrated simulation experience was noted between the pre- and post-simulation surveys. Prior experience in nursing was seen to significantly influence confidence.

Conclusions: Providing simulation encounters for large student cohorts although challenging, is achievable and rated highly by students. This study indicates that the integrated simulation experience has a positive impact on beginning students' feelings of confidence for managing similar patients in the clinical setting. Further research is required to explore how and why the guidance of the teacher and facilitator, and the use of a film which models nurse behaviour prior to the simulation, are viewed as of most assistance to beginning students. Additionally, future research must explore the impact simulation has on confidence and performance during and subsequent to clinical practicum. Simulation has a great capacity to augment the preparation of students for clinical practicum and for the development of clinical judgement, clinical skills and role identity.

\section{Key words}

Nursing education, Simulation, Beginning students, Preparation for practice

\section{I ntroduction}

The integration of simulation into nursing curricula has been growing rapidly in l nursing programs, internationally ${ }^{[1,2]}$. Limited access to clinical placements and a lack of consistency in students' experiences within the clinical setting 
increasingly require Bachelor of Nursing programs to be reliant on a combination of clinical and simulation experiences to facilitate the development of clinical judgement and practical skills ${ }^{[3,4]}$. The latest advances in simulation and associated pedagogies can deliver high levels of technical and psychological authenticity in a controlled and safe environment. This allows the student to act as a nurse (student or registered) and thereby internalise a sense of nursing role identity ${ }^{[5,6]}$. The literature is replete with evidence of simulation as a vehicle for teaching that suits the contemporary emphasis on active student learning, skill development and the quality and safety agenda ${ }^{[3,5,7-10]}$. Simulation experiences serve as preparation for clinical practice and complement the clinical experience in intensifying learning and facilitating reflection ${ }^{[3,5,7,8]}$. Little is known about how this is achieved in different learning environments particularly with large student cohorts, and how students apply their learning in practice ${ }^{[5,11]}$. It is important that learning outcomes from simulation be considered with regard to differences in course demands and resources, student characteristics and educational frameworks. By measuring known positive simulation outcomes, such as student confidence, and identifying those unique aspects of simulation delivery that contribute to student learning, the success of simulation in differing circumstances can be explored and shared.

\subsection{Student confidence as a positive outcome measure}

Implementing simulation experiences prior to episodes of clinical practice has been shown to assist students in developing confidence ${ }^{[1,10]}$. A number of studies have measured student confidence using quantitative methods. While typically these studies have involved small student numbers ${ }^{[7,12-15]}$, a study by Mould et al ${ }^{[16]}$ involved 219 third year nursing student participants and found that confidence scores increased by 1.45 on a 5 point scale $(p<.001)$ when students were exposed to a series of simulations scenarios. Similar positive results have been shown on confidence using mixed methods ${ }^{[17]}$ and focus groups ${ }^{[4,18]}$. Reilly and Spratt ${ }^{[18]}$ found that exposure to simulation prior to clinical helped students to seek opportunities to participate during practicum. Not all studies report positive changes related to confidence, such as, the findings of Brannan et al ${ }^{[13]}$ who found that confidence levels were not significantly enhanced following simulation. However, confidence is frequently associated with a successful learning experience involving simulation ${ }^{[16-18]}$.

Theories of Cognitive Development ${ }^{[19,20]}$, Social Learning ${ }^{[21]}$ and Constructivism ${ }^{[22]}$ offer insight into how the application of theory to practice, through simulation, allows students to construct knowledge and increase confidence. Constructivism, where learners build on their existing knowledge (assimilation) and construct schema in their minds to understand new knowledge (accommodation) underpins the use of patient case scenarios and authentic practice experiences in the nursing laboratories, clinical practice exams and facilitated clinical experiences ${ }^{[22]}$. Additionally, Social constructivism is reflected during team based patient simulations, where students engage with teachers and other participants to develop their own meaning ${ }^{[22]}$. Learning in this manner allows academics to scaffold and support student learning, then gradually withdraw support and direction to facilitate independence and confidence ${ }^{[2]}$. Further to this, educational frameworks that influence a whole of curriculum approach, into which simulation is nested, work to synthesise learning and provide a consistency of practice across learning experiences.

\subsection{An educational framework for clinical reasoning and judgement: relationship to simulation encounters and confidence}

Tanner's Model of Clinical Judgment accommodates situated learning in simulation and clinical experiences within a framework for nursing practice ${ }^{[23]}$. Awareness and confidence to act in practice settings develops over time within this framework, with expert nurses exhibiting a high level of intuitive thinking and clinical judgement in their practice ${ }^{[24]}$. Blum ${ }^{[12]}$ for example, found a significant increase in confidence levels when using the Lasater Clinical Judgment Rubric (based on Tanner's model) to measure students' self-confidence after exposure to high fidelity simulation. Fostering clinical reasoning and the ability to make clinical judgements is essential to the preparation of nursing students for clinical practice and development of their professional identity ${ }^{[3,4]}$. Development of such thinking and judgement, an integral component of nursing curricula, can be advanced through simulation learning encounters ${ }^{[5,7,8]}$. Integration of Tanner's 
framework across all elements of curricula, including simulation, provides a cohesive inter-related structure for learning and development of the professional nursing role ${ }^{[23,24]}$.

The presented paper seeks to describe the components of the integrated simulation experience which were of most assistance to students during their first simulated exposure. Further, this study aims to add to existing research through describing beginning students' confidence for practice before and after their first simulation encounter within a framework of clinical judgement and according to student characteristics.

\subsection{The simulation encounter}

The simulation encounter was designed to integrate and build on the learning objectives from all four core semester courses and utilize principles of Tanner's Model of Clinical Judgment ${ }^{[23]}$ as an underlying framework. All first year nursing students are required to participate in a three hour integrated simulation experience as part of the large cohort simulation week (SIM Week). Students were divided into groups of 12 and participated in two linked sessions: 1) skills review and 2) active participation simulation (see Figure 1). The skills review session allowed students to revise skills covered during the semester under the guidance and support of clinical nurses employed by the university (sessional clinical facilitators). Students worked through a series of activities at two clinical stations. The activities were based in two patient scenarios and included: communication with patients; infection control; manual handling; personal care; basic cardiovascular monitoring and patient education. During the session students role-played as student nurses and as the patient.

\begin{tabular}{|c|}
\hline SKILLS·REVIEW·SESSION \\
\hline $\begin{array}{c}\text { Scenario } \cdot 1 \\
\text { (6.students: } 1 \cdot \text { facilitator })\end{array}$ \\
\hline $\begin{array}{c}\text { Scenario } \cdot 2 \\
\text { (6.students: } 1 \cdot \text { facilitator })\end{array}$ \\
\hline Simulation $\cdot$ briefing $\cdot$ film \\
\hline ACTIVE·PARTICIPATION · SIMULATION \\
\hline 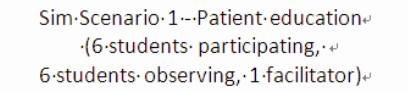 \\
\hline Scenario 1 . Debriefing \\
\hline 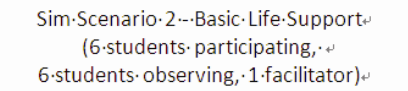 \\
\hline Scenario $\cdot 2 \cdot$ Debriefing \\
\hline
\end{tabular}

Figure 1. Large Cohort Simulation Encounter - Cycle Sequence

After the skills review session, students viewed a short film that depicted excerpts of the active simulation session in which students would subsequently participate. The film provided students with a visual concept of 'what simulation looked like' and examples of experienced nurse behaviours and interactions that students might apply to the clinical scenario. Faculty staff assisted in creating the film as a strategy to provide teachers with insight into the likely student experience and to ensure consistency of delivery. After watching the film, students self-selected roles for the active simulation and received role outlines (laminated and attached to lanyards) which specified the broad actions to be undertaken and additional prompts. This strategy provided structure for the novice students and allowed for more authentic responses to the unfolding simulation scenario. Such support however, did not diminish the necessity for students to interpret the situation and respond based on their judgments. 
Students participated in two active simulation scenarios based on case studies used throughout the semester courses. The first scenario focused on patient education where students role-played an interaction between a practice nurse, a teenager and his mother. Students participated in the roles of: a non-communicative adolescent who was disengaged with his chronic asthma management; an anxious mother who attempted to monopolise the conversation; and a practice nurse who was required to educate the adolescent about asthma while managing the interaction. The scenario was run twice with the practice nurse altering their approach from poor communication to good communication, thus illustrating the role and skills of the nurse in managing similar situations.

The second scenario focused on basic life support with students taking on various roles, as nurses working in a general practice (local medical service) setting and family members present during deterioration of their relative (the manikin). Students in the practice nurse roles were required to communicate with the patient and family and then proceed with basic life support when the patient became unconscious. All students had completed a deteriorating patient laboratory session in the previous week. Students in the family member roles were instructed to depict distress as the patient deteriorated, requiring the practice nurses to manage the family members in addition to the unconscious patient. The family members brought realism to the community setting and also allowed students to explore the experience of being a family member during patient deterioration. A faculty member with simulation training was present in the lab during the scenarios to provide directive prompts. Debriefing and reflection occurred immediately after each simulation scenario (see Figure 1). Debriefing was facilitated by faculty staff to draw out the core concepts of communicating with patients and families, the role of the nurse in education, teamwork, and basic life support. The presence of family members in an acute deterioration was also discussed as a broader concept.

The practical components of the skills review and simulation encounter would be applied in the students' subsequent first clinical placement. All activities within the simulation encounter required students to consider and construct clinical judgements through noticing, interpreting and responding to cues from each other and the context of the scenarios. This process was underpinned by Tanner's Model of Clinical Judgment (2006). Students were well acquainted with this model as it is a fundamental framework for teaching and learning across all first semester courses.

\subsection{Providing quality simulation experiences for large cohorts}

At the time of this study over 500 students were enrolled in the first year of a Bachelor of Nursing program at an Australian university. Simulation is integrated across the curricula with students participating in a developmental simulation as part of their first and second semester course requirements. All students took active roles in the simulation experience and acted as observers to provide feedback to others. To enable all students to participate, 42 cycles of simulation were run over a 'SIM week'. This activity required deliberate management of resources to include students in active participation. As previously reported ${ }^{[4]}$ strategies included: no face-to-face classes during 'SIM week' so that faculty were available to deliver the simulation; deliberate use of clinical facilitators to assist with the skills review sessions; and a small increase in support staffing to manage laboratory requirements. The use of clinical facilitators brought clinical authenticity to the simulation and provided students with an opportunity to interact with experienced nurses who would be overseeing their first clinical placement. Time was provided for students to ask facilitators questions about the acute care clinical practicum to follow. Anecdotally, the clinical facilitators involved in the simulation voiced greater understanding of simulation as a learning and teaching strategy, and an increased appreciation of the learning needs of the student cohort they would soon support in the clinical field.

\subsection{Purpose and specific research questions}

The purpose of this study was to describe the delivery of a large cohort integrated simulation experience to beginning nursing students and consequent changes in confidence in caring for patients similar to those in the simulation encounter.

Specific research questions: 
- Which components of the integrated simulation experience were of most assistance to students' learning during the overall simulation experience?

- Does beginning students' confidence for managing patients similar to those in their first simulation encounter, change after the integrated simulation experience?

- Do enrolment status, educational qualification and previous experience in nursing have an influence on the change in beginning nursing students' confidence after the integrated simulation experience?

\section{Methods}

\subsection{Study setting and participants}

This study is part of a larger longitudinal research project evaluating simulation learning experiences for large cohorts of nursing students at an Australian university. At the time of this study, 517 students were enrolled in the first year of a three year Bachelor of Nursing program. All students were required to participate in a simulation encounter prior to entering the clinical environment. All students were invited to complete a self-report online survey before and after their simulation encounter. 452 (87\%) students completed either a pre or post-simulation survey. The majority of students were aged under $21(217,53 \%)$ which is consistent with a high proportion of participants indicating high school as their highest level of education (238,58.5\%). Similarly, the overwhelming majority of participants had no nursing experience prior to entering the program (318, 77.9\%) (see Table 1). The proportion of males to females was 1:7 which is consistent with male enrolment numbers in nursing in Australia ${ }^{[25]}$.

Table 1. Participant Demographical Information

\begin{tabular}{|c|c|c|}
\hline Demographics & Frequency & $\%$ \\
\hline $\begin{array}{l}\text { Age } \\
\text { Mean age (SD) } \\
\text { Mode age } \\
\mathrm{n}=412\end{array}$ & $\begin{array}{l}23.23(6.148) \\
18\end{array}$ & - \\
\hline $\begin{array}{l}\text { Gender } \\
\text { Male } \\
\text { Female } \\
\mathrm{n}=408\end{array}$ & $\begin{array}{l}50 \\
358\end{array}$ & $\begin{array}{l}12.3 \\
87.7\end{array}$ \\
\hline $\begin{array}{l}\text { Highest Qualification } \\
\text { Higher education } \\
\text { Technical college } \\
\text { High School } \\
\text { n=407 }\end{array}$ & $\begin{array}{l}111 \\
58 \\
238\end{array}$ & $\begin{array}{l}27.3 \\
14.3 \\
58.5\end{array}$ \\
\hline $\begin{array}{l}\text { Enrolment status } \\
\text { International student } \\
\text { Local student } \\
\mathrm{n}=432\end{array}$ & $\begin{array}{l}203 \\
229\end{array}$ & $\begin{array}{l}47 \\
53\end{array}$ \\
\hline $\begin{array}{l}\text { Previous experience in nursing } \\
\text { No } \\
\text { Yes } \\
\text { Nursing assistant } \\
\text { Formal carer } \\
\text { International nursing registration } \\
\text { Previously a nursing student } \\
\text { Enrolled nurse } \\
\mathrm{n}=408\end{array}$ & $\begin{array}{l}318 \\
90 \\
54 \\
11 \\
18 \\
6 \\
1\end{array}$ & $\begin{array}{l}77.9 \\
22.0 \\
13.2 \\
2.7 \\
4.4 \\
1.5 \\
0.2\end{array}$ \\
\hline
\end{tabular}




\subsection{Self-report simulation survey}

The self-report survey was developed and tested for the purpose of this study. The design and questions were reviewed by a panel that held expert knowledge in simulation strategies, higher education pedagogy and clinical nursing. The survey collected information on the contribution of the components of the integrated simulation experience to student learning, the change in students' confidence in caring for patients like those in the simulation and students' overall satisfaction with the simulation encounter. Both pre and post-simulation surveys were accessible through the secured university online course portal and were advertised during lectures, laboratory classes and through email announcements. The presimulation survey contained seven questions and collected student identification number (to be removed prior to analysis), demographic data including gender, age, if a local or international student, highest educational qualification prior to entering the program and previous experience in nursing (see Table 1). Confidence was measured in response to a single question posed in both the pre and post-simulation surveys which asked participants' to rate their confidence for caring for patients similar to those in the simulation experience on a 10-point Likert scale ( 0 being no confidence to 10 being very confident).

In the post-simulation survey students were asked to rate the contribution of the nine integrated simulation components to learning according to three descriptors: no assistance, satisfactory assistance and most assistance (see Figure 2). Participants were also asked to rate their overall experience of the simulation on a 10-point Likert scale $(0=$ Not good through to $10=$ Very good) and the extent to which having participated in the simulation would assist them when going out on their upcoming clinical placement $(0=$ No assistance through to $10=$ Very much assistance $)$.

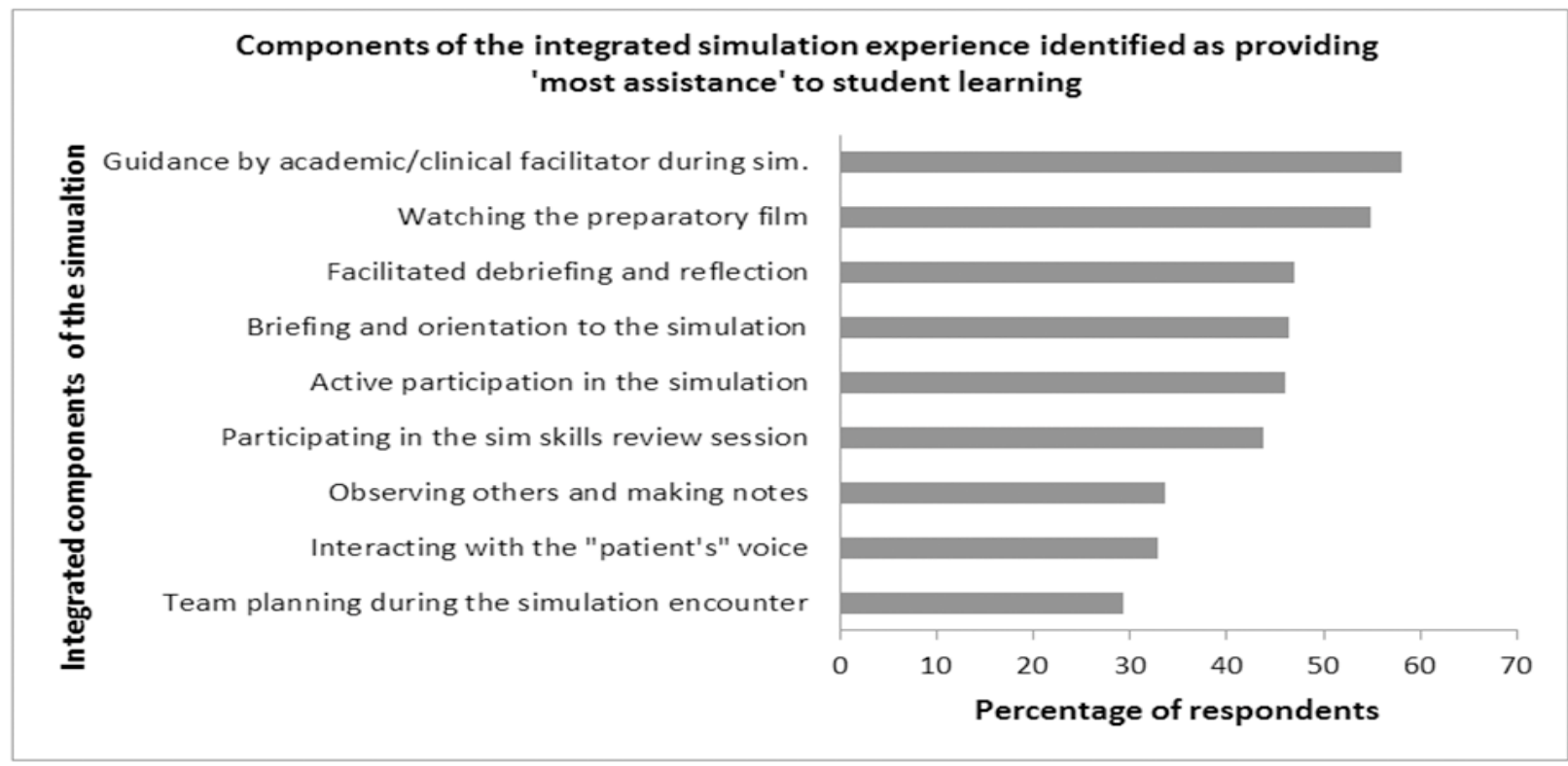

Figure 2. Components of the Integrated Simulation Experience Identified as Providing 'Most Assistance' to Student Learning

\subsection{Ethical considerations}

Ethical approval was granted by the university's Human Research Ethics Committee (HREC 2010-406N). Students signed confidentiality and consent forms for participation in the simulation encounter and the research respectively. The identities of respondents were maintained as confidential throughout the data collection and analyses processes. Data were de-identified prior to analyses. Participants were made aware that participation in this study was voluntary and that they could withdraw at any time. Participants were informed that their responses would remain confidential at all times and 
their responses would be de-identified prior to analyses. Furthermore, students were informed that participation in this study would have no bearing on their grades or credits towards their courses.

\subsection{Data management and analysis}

All data were entered and analyzed using the Statistical Package for Social Science (SPSS) Version 19.0 for Windows (SPSS Inc, Chicago, IL, USA). Data from the survey were stored on a secure university website. A master list is stored in a locked cabinet in the research office at the University for re-identification of data for removal if necessary. Study data is only accessible by the investigators. All records will be kept for the time period mandated by standard protocol (5 years) and will be permanently deleted upon completion of the term. Paper copies will be shredded and computer files deleted.

Continuous data with normal distribution were analyzed using independent $t$ test and a signed ranked test. Sub-group analyses were undertaken using a one-way between group multivariate analysis of variance. All other data were reported using simple descriptive statistics.

\section{Results}

\subsection{Educational components that assisted in the learning experience}

Participants were asked to identify the level of assistance of the integrated simulation components in relation to their learning experience. The overwhelming majority of participants (73\%-93\%) rated each component as either of satisfactory assistance or of most assistance. Only a minority of participants noted any component to be of no assistance. The most highly rated components of the integrated simulation experience were: guidance by the academic or facilitator, and watching the pre-simulation film (see Figure 2). These findings require further investigation to determine the reasons for the relative rankings of these two strategies for novice students in light of the remaining components.

\subsection{Confidence in caring for individuals like those in the simulation experience}

A paired-samples t-test was conducted to evaluate the change in students' confidence in caring for patients like those in the simulation. 261 (54\%) respondents answered the questions regarding confidence in both pre and post surveys, there was a statistically significant increase in the confidence of the overall student cohort of 0.85 on a point scale from before the simulation (mean $(M)=5.71$, standard deviation $(S D)=1.719)$ to after the simulation encounter $(M=6.56, S D=1.436$, $\mathrm{t}(260)=7.916, p<.0005)$.

Confidence levels were further analysed in relation to participants' previous experience in nursing, international enrolment status, and level of education prior to enrolling in the nursing program. One way between groups multivariate analyses of variance were performed to investigate the impact of these variables on confidence prior to entering the simulation and confidence after the simulation experience. Preliminary assumption testing was conducted to check normality, linearity, univariate, multivariate outliers, and multicollinearity, with no serious violations noted. A statistically significant difference was observed in overall confidence between those who had no experience in nursing as compared with those who had some experience prior to entering the course, $\mathrm{F}(2,255)=8.63, p<0.0001$; Wilks' Lambda $=0.94$; partial eta squared $=0.063$. When pre-simulation and post-simulation confidence were considered separately a statistical significance was seen in mean pre-confidence levels only, using an adjusted Bonferroni alpha level of $0.017(\mathrm{~F}(1,256)=16.85$, $p=.0001$, partial eta squared $=0.062$ ) (see Table 2). This indicated that those without prior exposure in the clinical field, increased their confidence to the same level indicated by those who entered the course with a background in healthcare. No statistically significant difference was seen in confidence between international and local students $(\mathrm{F}(2,258)=1.79$, $p=0.14)$, or confidence between participants with differing levels of education prior to entering the nursing course ( $\mathrm{F}$ $(4,504)=1.29, p=0.27)$. 
Table 2. 'Confidence in Caring for Similar Patients' in the Scores Pre and Post Simulation

\begin{tabular}{llll}
\hline Previous experience in nursing & $\begin{array}{l}\text { No }(\mathbf{n}=258) \\
\text { Mean (SD) }\end{array}$ & $\begin{array}{l}\text { Yes (n=258) } \\
\text { Mean (SD) }\end{array}$ & p value \\
\hline Pre-simulation confidence & $5.50(1.64)$ & $6.54(1.77)$ & $<0.0001^{*}$ \\
Post-simulation confidence & $6.48(1.44)$ & $6.95(1.37)$ & 0.029 \\
\hline
\end{tabular}

*Significance adjusted Bonferroni alpha level 0.017

\subsection{Overall satisfaction and contribution of simulation to clinical practice}

Students were also asked to what degree they felt the simulation would help them in preparing for their upcoming clinical placement. The overwhelming majority of students rated the assistance of the simulation highly, with 344 (83.3\%) scoring assistance as seven or above out of ten. Similarly, students were highly satisfied with the simulation encounter, with 98 (85\%) of a total 116 respondents to this question scoring satisfaction as seven or above out of ten.

\section{Discussion}

Limited access to clinical placements and a lack of consistency in students' experiences within the clinical setting increasingly require Bachelor of Nursing programs to be reliant on a combination of clinical and simulation experiences to facilitate the development of clinical judgement and practice skills ${ }^{[3,4]}$. This study sought to contribute to previous research by exploring the educational strategies which were of most assistance to learning during an integrated simulation experience and beginning nursing students' confidence in relation to their first simulation ${ }^{[26]}$.

Students described the components of most assistance to their learning as 'guidance provided by faculty or clinical facilitator' and 'viewing the preparatory film'. The positive role of the academic and facilitator in scaffolding and guiding simulation activities has been highlighted in the literature and reported in another paper associated with this study ${ }^{[2,4]}$. Socialization with experienced nurse faculty and other students, as well as observation of model behavior through the film may reflect development and learning through social constructivism ${ }^{[22]}$. Additionally students learning and development of confidence through legitimate peripheral participation in a community of practice reflects the theory of Situated Learning ${ }^{[27]}$. Team based simulations with students participating in a variety of roles (including observing), then participating in facilitated debriefing and reflection, provide an opportunity for students to discuss and learn from multiple perspectives $^{[2,7,16,27]}$.

Students' feeling of confidence in regard to managing patients like those encountered in the simulation was seen to statistically improve across the cohort as a whole. This result suggests that simulations based within a critical thinking framework that involve active participation and reflection, provide a positive opportunity for students to develop situational confidence within a safe and controlled environment ${ }^{[1,5,10,22,24]}$. The confidence of beginning nursing students in caring for patients similar to those in the simulation were seen to be significantly higher in students who had nursing experience prior to entering the Bachelor of Nursing program, which may be related to previous situational learning. Students who did not have prior nursing experience were seen to increase their confidence significantly over the simulation encounter and significantly in comparison to the other group. This indicated that over the simulation encounter, those without prior exposure in the clinical field increased their confidence to the same level as those who entered the course with a background in healthcare, strengthening the argument for the use of this type of developmental learning in preparing students for the clinical field ${ }^{[24,25]}$. In further support of the benefit of this activity, over $80 \%$ or students reported that the experience would strongly contribute to this aim. Further research is required to explore the impact of modeled behavior as well as other components of the integrated simulation experience and how these correlate with learning, confidence and coping with the clinical environment ${ }^{[1,4]}$. 


\subsection{Simulation as part of nursing curricula}

Providing high quality simulations to large nursing student cohorts is not without logistical and resource challenges. The university has worked closely with the simulation team to create a sustainable simulation program which provides an equitable experience for all students. One survey question sought students' opinion about their simulation experience provided via the strategies outlined in this paper. That $85 \%$ of responses indicated high satisfaction with the integrated simulation experience is validation of the delivery strategies for large cohorts of novice nursing students. Anecdotally, the involvement of clinical facilitators and faculty staff in the simulation encounters has improved staff understanding of simulation and importantly increased appreciation of the learning needs of the student entering the clinical field.

Curriculum development at this university actively sought to integrate a research based framework of clinical judgement from the outset of the Bachelor of Nursing program. This promoted students' ability to intuitively recognize situational and meaningful elements from practical encounters ${ }^{[24]}$. These core skills, enhanced through simulation, are essential in the preparation and transition of nursing students into clinical practice and the professional role ${ }^{[3,4,23,26]}$.

\subsection{Limitations and recommendations for future research}

The use of a purpose developed and self-report survey has its limitations. However, this study has provided understanding of students' perspectives of the components that most assisted learning during their first integrated simulation experience. A recent literature review of the effectiveness of simulation learning experiences in pre-licensure health care students additionally highlights the need to explore the effectiveness of simulations to prepare students for real-life experiences ${ }^{[1]}$. Our understanding of simulation must expand beyond the simulation encounter itself, with future research giving greater attention to how curricula can optimize the combined effect of simulation learning and clinical experience. Future tracking of students' performance across their program and specifically the contribution of simulation to learning and clinical practice would provide greater insight into the wider benefits of this powerful teaching and learning strategy. Validation of the surveys would strengthen the instrument for use with larger groups and in other settings.

\section{Conclusions}

Providing simulation encounters for large student cohorts although challenging, is achievable. This study indicates that simulation does have a positive impact on beginning students' feelings of confidence about managing similar patients in the clinical setting. Further research is required to explore how and why the guidance of the facilitator and the use of a film which models nurse behaviour prior to the simulation are viewed as most assistance to beginning students as part of the learning experience. Additionally, future research should explore the impact of simulation on confidence and performance within and subsequent to clinical practicum. Simulation has a great capacity to augment the preparation of students for clinical practicum and for the development of clinical judgement, clinical skills and role identity.

\section{Acknowledgements}

We acknowledge and thank Oanh Trinh and Associate Professor Robyn Gallagher respectively for their assistance in online survey management and statistical analysis.

\section{References}

[1] Laschinger S, Medves J, Pulling C, McGraw R, Waytuck B, Harrison MB, et al. Effectiveness of simulation on health profession students' knowledge, skills, confidence and satisfaction. International Journal of Evidence-Based Healthcare. 2008 ; 6: $278-302$. PMid:21631826 http://dx.doi.org/10.1111/j.1744-1609.2008.00108.x

[2] Sanders D, and Sugg Welk D. Strategies to scaffold student learning: applying Vygotsky's zone of proximal development. Nurse Educator. 2005; 30: 203-7. PMid:16170261 http://dx.doi.org/10.1097/00006223-200509000-00007 
[3] Melnyk BM, Evidence to Support the Use of Patient Simulation to Enhance Clinical Practice Skills and Competency in Health Care Professionals and Students. Worldviews on Evidence-Based Nursing. 2008; 5: 49-52. http://dx.doi.org/10.1111/j.1741-6787.2008.00112.x

[4] Rochester, SF, Kelly, MA, Disler, RT, White, HL, Forber, J \& Matiuk, S. 'Providing simulation experiences for large cohorts of 1st year nursing students: Evaluating quality and impact', Collegian. 2012; 19: 117-124. PMid:23101345 http://dx.doi.org/10.1016/j.colegn.2012.05.004

[5] Berragan L. Simulation: An effective pedagogical approach for nursing? Nurse Education Today, in press. PMid:21334797

[6] Mooney M. Newly qualified Irish nurses' interpretation of their preparation and experiences of registration. Journal of Clinical Nursing. 2007; 16: 1610-17. PMid:17727582 http://dx.doi.org/10.1111/j.1365-2702.2007.01691.x

[7] McCaughey CS and Traynor MK. The role of simulation in nurse education. Nurse Education Today. 2010 ; 30: 827-32. PMid:20483188 http://dx.doi.org/10.1016/j.nedt.2010.03.005

[8] Ricketts B. The role of simulation for learning within pre-registration nursing education - A literature review. Nurse Education Today, in press. PMid:21074297

[9] Cooper S, Kinsman L, Buykx P, McConnell-Henry T, Endacott R, and Scholes J. Managing the deteriorating patient in a simulated environment: nursing students' knowledge, skill and situation awareness. Journal of Clinical Nursing. 2010; 19: 2309-18. PMid:20659205 http://dx.doi.org/10.1111/j.1365-2702.2009.03164.x

[10] Gantt L and Webb-Corbett R. Using simulation to teach patient safety behaviors in undergraduate nursing education. Journal of Nursing Education. 2010; 49: 48 - 51. PMid:19810666 http://dx.doi.org/10.3928/01484834-20090918-10

[11] Weaver A. High-fidelity patient simulation in nursing education: An integrative review. Nursing Education Perspectives. 2011; 32: 37-40. PMid:21473481 http://dx.doi.org/10.5480/1536-5026-32.1.37

[12] Blum CA, Borglund, S., and Parcells, D. High-fidelity nursing simulation: Impact on student self-confidence and clinical competence. International Journal of Nursing Education Scholarship. 2010; 7: 1-16. PMid:20597857 http://dx.doi.org/10.2202/1548-923X.2035

[13] Brannan JD, White A, and Bezanson JL. Simulator Effects on Cognitive Skills and Confidence Levels. Journal of Nursing Education. 2008; 47: 495-500. PMid:19010047 http://dx.doi.org/10.3928/01484834-20081101-01

[14] Schoening AM, Sittner BJ, and Todd MJB. Simulated Clinical Experience: Nursing Students' Perceptions and the Educators' Role. Nurse Educator November/December. 2006; 31: 253-58. http://dx.doi.org/10.1097/00006223-200611000-00008

[15] Tiffen J, Graf N, and Corbridge S. Effectiveness of a Low-fidelity Simulation Experience in Building Confidence among Advanced Practice Nursing Graduate Students. Clinical Simulation in Nursing. 2009; 5: e113-e17. http://dx.doi.org/10.1016/j.ecns.2009.01.009

[16] Mould J, White H, and Gallagher R. Evaluation of a critical care simulation series for undergraduate nursing students. Contemporary Nurse: A Journal for the Australian Nursing Profession. 2011; 38: 180-90.

[17] Elfrink VL, Nininger J, Rohig L, and Lee J. The CASE for Group Planning in Human Patient Simulation. Nursing Education Perspectives. 2009; 30: 83-86. PMid:19476070

[18] Reilly A and Spratt C. The perceptions of undergraduate student nurses of high-fidelity simulation-based learning: A case report from the University of Tasmania. Nurse Education Today. 2007; 27: 542-50. PMid:17069935 http://dx.doi.org/10.1016/j.nedt.2006.08.015

[19] Piaget J and Inhelder B, The psychology of the child. 1969, New York: Basic Books.

[20] Vygotsky L. Mind in society: The development of higher psychological processes. 1978, Cambridge, MA: Harvard University Press.

[21] Bandura A. Social Learning Theory. 1977, Engelwood Cliffs, NJ Prentice Hall.

[22] Bradley P and Postlethwaite K, Simulation in clinical learning. Medical Education. 2003; 37: 1-5. PMid:14641632 http://dx.doi.org/10.1046/j.1365-2923.37.s1.1.x

[23] Tanner CA. Thinking like a nurse: A research-based model of clinical judgment in nursing. Journal of Nursing Education. 2006; 45: 204 - 21. PMid:16780008

[24] Benner P, Tanner CA, and Chesla CA. Expertise in nursing practice: caring, clinical judgment and ethics. 2nd ed. 2009, New York: Springer.

[25] Mehta H and Robinson K. Male nursing students' expectations, experiences and social justice issues., in Learning, Teaching and Social Justice in Higher Education, N. Riseman, S. Rechter, and E. Warne, Editors. 2010, University of Melbourne eScholarship: Melbourne.

[26] Rochester S, Kelly M, Disler R, White H, Forber J, and Matiuk S. Providing simulation experiences for large cohorts of 1st year nursing students: Evaluating quality and impact. Collegian. 2012; 19: 117-24. PMid:23101345 http://dx.doi.org/10.1016/j.colegn.2012.05.004

[27] Lave J and Wenger E, Situated learning: legitimate peripheral participation. 1991, Cambridge: Cambridge University Press. http://dx.doi.org/10.1017/CBO9780511815355 